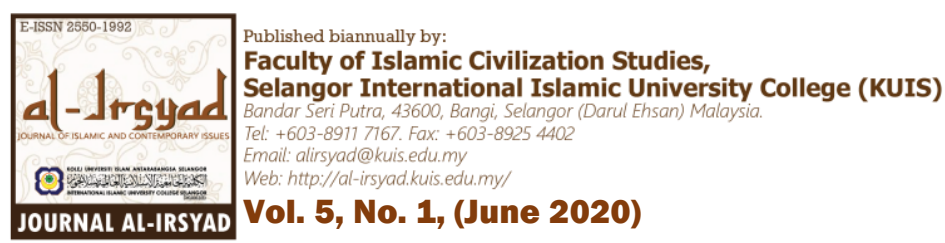

\title{
Maqam Sabar dalam Psikoterapi Pemulihan Pedofilia: Kajian Terhadap Qüt al-Qulūb Syeikh Abū Ṭālib Al-Makkī (W. 996 M)
}

\section{[Maqām al-Ṣabr in the Paedophilia Rehabilitation Psychotherapy: A Study on Qüt al-Qulüb by Syeikh Abū Ṭälib al-Makkī(D. 996 CE)]}

\section{Abur Hamdi Usman ${ }^{1 *}$, Rosni Wazir ${ }^{2}$, Syarul Azman Shaharuddin ${ }^{1}$, Norsaleha Mohd Salleh", Mohd Norzi Nasir² \& Muhammad Fakhrur Razi Shahabudin²}

\footnotetext{
${ }^{1}$ Department of Da'wah \& Usuluddin, Faculty of Islamic Studies and Civilization, Kolej Universiti Islam Antarabangsa Selangor (KUIS), Malaysia.
}

2 Department of Al-Quran \& Al-Sunnah, Faculty of Islamic Studies and Civilization, Kolej Universiti Islam Antarabangsa Selangor (KUIS), Malaysia.

* Corresponding Author: Dr. Abur Hamdi Usman. Faculty of Islamic Studies and Civilization, Kolej Universiti Islam Antarabangsa Selangor (KUIS), Malaysia. Tel: (+60) 011-1907 0551. Email: aburhamdi@kuis.edu.my, ORCID ID: 0000-0001-5179-1648.

\section{Keywords:}

Maqām; Patient;

Psychotherapy;

Paedophilia; Qūt al-Qulūb;

Syeikh Abū Tẫlib al-Makkī
ABSTRACT

Sheikh Abū Tālib al-Makkī was a scholar of Sufism respected in the Islamic world. His work, Qūt al-Qulūb, is a major source of reference to sages of the past and present. Many Islamic scholars use Maqamāt al-Ahwāl's theory as a module and rehabilitation guideline for a number of diseases that affect the human soul. Paedophilia, according to the Diagnostic and Statistical Manual Disorder (DSM-5) falls into a category of mental disorders, with some experts considering paedophiles as being mentally insane. In this regard, the main objective of this study was to analyse the implementation of maqām al-șabr (stage of patience), according to al-Makkī, as a concept of paedophilia rehabilitation psychotherapy. Using qualitative methods, this study found maqām al-șabr to be a crucial element in the recovery from paedophilia. Therefore, this article hopes to integrate the elements of patiencee stage with rehabilitation psychotherapy to develop one of the best treatment modules in the rehabilitation of paedophilia in Malaysia.

\section{Kata Kunci:}

Maqam; Sabar; Psikoterapi; Pedofilia; Qūt al-Qulūb; Syeikh Abū Țālib al-Makkī
Syeikh $A b \bar{u}$ Tălib al-Makkī merupakan ulama tasawuf yang disegani dunia Islam, malah karyanya Qūt al-Qulūb menjadi sumber utama golongan sufi mutaqaddimīn dan muta'akhkhirīn. Sebahagian besar sarjana Islam menggunakan teori maqamat alAhwal sebagai modul dan rehab untuk beberapa penyakit melibatkan kejiwaan manusia. Pedofilia pula menurut Diagnostic and Statistical Manual Disorder (DSM-5) termasuk dalam kategori gangguan mental, malah sebahagian pakar menganggap pedofil sebagai orang gila. Sehubungan dengan itu, objektif utama kajian ini untuk menganalisis implementasi maqam sabar menurut alMakkī sebagai konsep psikoterapi pemulihan pedofilia. Dengan menggunakan metode kualitatif, kajian ini mendapati maqam sabar antara elemen penting dalam pemulihan pedofilia. Justeru artikel ini diharap dapat menyatupadukan elemen maqam sabar dan 


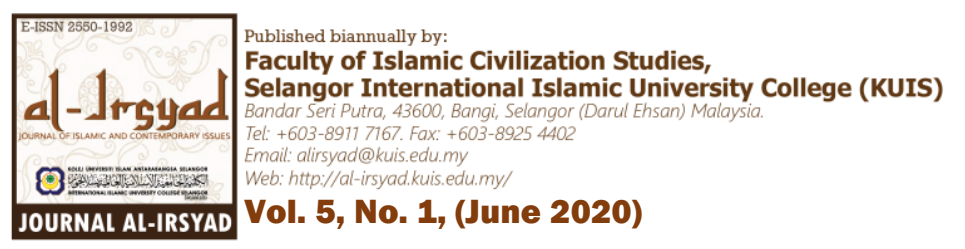

psikoterapi pemulihan, sekali gus menjadi satu modul rawatan yang terbaik dalam pemulihan ketagihan seksual golongan pedofilia di Malaysia.

\section{Pendahuluan}

Isu pedofilia merupakan sebuah kumpulan seksual songsang baru yang berada dalam kehidupan masyarakat kini. Sebahagian pihak menganggap ia adalah satu ketagihan yang telah dimodenkan melalui proses revolusi dari semasa ke semasa. Sehingga hari ini, kumpulan seks songsang ini menjadi satu perbuatan jenayah yang perlu dihadapkan ke muka pengadilan. Namun, kumpulan seperti LGBT (lesbian, gay, biseksual dan transgender) mula memberi tempat kepada kumpulan pedofilia ini dalam klausa hak kebebasan bersuara. Sedangkan ia adalah perbuatan yang tidak bermoral dan tidak berperikemanusiaan (Usman, et. al., 2019).

Jenayah pedofilia dalam dunia teknologi dan global ini dilihat semakin meruncing. Malah Malaysia antara negara yang turut sama menerima kesannya, dengan peningkatan kes saban tahun dari kalangan anak tempatan. Statistik dari Polis Diraja Malaysia (PDRM) menunjukkan sebanyak 22,234 kes penderaan seksual kanak-kanak telah direkodkan dari tahun 2010 hingga Mei 2017, iaitu dengan purata kes sebanyak 3,176 kes setahun. Jumlah tersebut mewakili empat kategori penderaan seksual iaitu rogol sebanyak 13,272 kes diikuti cabul sebanyak 6,014 kes, sumbang mahram sebanyak 1,796 kes, dan perbuatan luar tabii sebanyak 1,152 kes (Mohamed Ali, 2019; Usman, A. H., \& Shahabudin, M.F.R., 2019).

Akhbar tempatan Malaysia, News Straits Times bertajuk "Address Weakness to Protect Our Children" melaporkan bahawa Malaysia merupakan antara pusat pengedaran bahan pornografi kanak-kanak yang terbesar di Asia Tenggara berikutan jumlah sumber laman web sesarang dari Kuala Lumpur yang mengedar bahan-bahan tersebut (Thye, 2016). Malaysian Communications and Multimedia Commission (MCMC) telah menerima 652 laporan pada tahun 2015 dan 151 pada bulan Mac 2016 berkenaan penyebaran foto dan video pornografi semua lingkungan umur termasuk kanak-kanak di Malaysia (Shukor, Shah, \& Musa, 2017). Unit Anti-Pedofilia Jawatankuasa Argos Australia mendapati bahawa hanya enam peratus daripada pesalah laku jenayah seksual kanak-kanak telah disabitkan kesalahan atas kegiatan pedofilia yang telah dilakukan berikutan kelemahan penguatkuasaan undang-undang dan polisi perlindungan kanak-kanak di Malaysia (Reuters, 2016).

Justeru itu, artikel ini menganalisis konsep tasawuf yang dibahaskan oleh Syeikh Abū Tāilib alMakkī (w. 996 M.) sebagai salah satu kaedah pencegahan dan rawatan alternatif bagi pesakit pedofil. Pengkaji memfokuskan perbincangan terhadap maqam sabar yang diulas oleh al-Makkī dalam karyanya $Q \bar{u} t$ al-Qulūb sebagai tunjang utama perbahasan artikel ini.

\section{Syeikh Abū Țālib al-Makkī: Biografi Ringkas Sufi Agung}

Syeikh al-Makkī merupakan ahli tasawuf yang memperkenalkan konsep Maqāmāt al-Aḥwāl dalam karyanya. Beliau dikenali sebagai Abū Țālib al-Makkī dan nama sebenar beliau ialah Abū Țālib Muhammad Ibn 'Ali Ibn 'Atiyyah al-Harīth al-'Ajāmī al-Makkī. Ibn Khallikān (1977) menyatakan bahawa al-Makkī dilahirkan di wilayah al-Jibal satu daerah yang terletak antara kota Baghdad dan Wasith. Namun tarikh kelahiran al-Makkī secara faktanya tidak dapat ditentukan disebabkan tidak banyak penulisan atau maklumat mengenai kehidupan awal beliau (Ibn Khallikān, 1977), tetapi dikatakan bahawa al-Makkī sempat hidup sezaman dengan Ibn Sālim (350 H/960 M).

Al-Makkī mendapat pendidikan awal daripada Abū Sa‘īd ibn al-‘Arabī (341 H/950 M) (Mohd Amin, 1991). Setelah itu, beliau telah berhijrah ke Mekah bersama-sama keluarganya ketika masih kecil. Setelah sekian lama menjalankan kehidupan dan menimba ilmu di Mekah, beliau membuat keputusan untuk berhijrah pula ke Basrah dan seterusnya ke Baghdad di Iraq bagi tujuan berdakwah dan menyampaikan ilmu-ilmu, khususnya ilmu tasawuf (Bowering, 1980).

Gelaran al-Makkī sebenarnya dinisbahkan kepada seorang sufi yang datang dari Mekah. Sementara nama al-Harith merupakan nasabnya, iaitu dari keturunan suku al-Harith, salah satu dari suku yang terdapat di tanah Arab (Azra, 2008). Manakala gelaran al-'Ajāmī pula dinisbahkan kepada sekumpulan penduduk yang tidak bertutur dalam bahasa Arab terutama bagi mereka yang tinggal di wilayah Iran. Kehidupan dan pendidikannya tidak banyak dibincangkan oleh pengkaji sufi. Tetapi beliau diakui oleh ramai tokoh tasawuf 


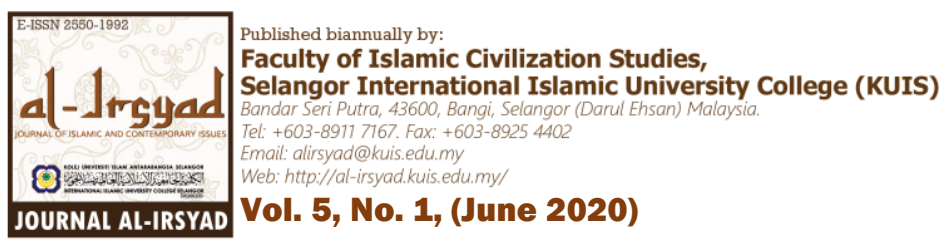

sebagai tokoh sufi yang tekun dan rajin dalam mendalami dan mengkaji ilmu-ilmu keagamaan, sehingga beliau dapat menguasai ilmu tersebut. Di antara ilmu tersebut ialah Tauhid, Hadis, Feqah, dan banyak terlibat dalam bidang tasawuf (Azra, 2008; al-Makkī, 1997).

Al-Makkī meninggal dunia pada 6 Jamadil Akhir tahun 386 H bersamaan dengan 966 M (al-Hanbalī, 1932), setelah hidup beberapa lama di Baghdad (Annemarie, 1975). Beliau dikatakan telah dimakamkan di bahagian tenggara Baghdad. Sesetengah pendapat menyatakan al-Makkī dimakamkan di kawasan perkuburan Maliki (Bowering, 1980). Malah, ada juga pendapat yang menyatakan al-Makkī dimakamkan di Lembah Tigris (al-JawZī, 1939).

Ketokohan al-Makkī dalam bidang tasawuf diakui oleh ramai sarjana Islam dan juga barat. Idea pemikiran yang dibawakan oleh al-Makkī dijadikan sebagai rujukan dan panduan kepada ahli sufi selepasnya. Kitab Qüt al-Qulūb, karya agung al-Makkī dalam bidang tasawuf telah menonjolkan elemen-elemen spiritual dan pengalaman kerohanian (Stapa, 2004) yang teratur dan sistematik dalam doktrin kesufian dan telah memberi pengaruh yang besar terhadap karya sufi seterusnya (Smith, 1984).

\section{Maqam Sabar}

Orang yang beriman mempunyai kelebihan kekuatan dalam bersabar menghadapi ujian dan cubaan, kerana dia yakin bahawa hanya Allah SWT sahaja yang mampu menyelamatkan dan memberikan jalan keluar daripada dugaan tersebut, sekali gus berharap akan mendapatkan pahala di sisiNya dan akan menambah ketinggian darajatnya di akhirat kelak (Usman \& Ahmad, 2019).

Maqam sabar merupakan salah satu unsur dalam merealisasikan maqam taubat iaitu seseorang yang berdosa perlulah menahan diri dari hawa nafsu untuk melakukan perkara-perkara yang dilarang. Pengertian sabar menurut al-Makkī ialah menahan diri dari hawa nafsu serta menekan diri agar tekun dalam beramal. Malah, sabar juga dapat diertikan sebagai bersungguh-sungguh dalam menghadapi dugaan dan ujian yang menimpa dalam kehidupan. Maka yang demikian, kesungguhan seseorang hamba dalam menahan diri dari hawa nafsu dan menghadapi ujian akan menumbuhkan ketaatan kepada Allah SWT di samping bersabar dalam membaiki akhlak buruk kepada akhlak yang mulia dalam pergaulan dan kelakuan (al-Makkī, 1997).

Dengan kesungguhan seseorang itu dalam sabar akan menumbuhkan ketaatan kepada Allah SWT dalam bentuk penyerahan diri kepadaNya. Penyerahan diri ini dapat dilihat dari pelbagai aspek iaitu menahan diri dalam melakukan perbuatan keji dan mungkar seperti sabar dalam memerangi hawa nafsu, sabar dalam kecintaan yang melampau terhadap dunia dan sabar supaya sentiasa berada di jalan Allah SWT dalam mengendalikan lidah (kata-kata), hati, tindakan dan sebagainya (al-Makkī, 1997). Dalam pelatihan diri untuk bersabar ini, secara tidak sedar seseorang itu telah merangkumi jalan-jalan taubat yang telah dijelaskan oleh alMakkī (Syed Muhsin, 2017).

Perkataan sabar disebutkan oleh Allah SWT sebanyak 90 kali di dalam al-Quran ('Abd al-Bāqī, 1981). alMakkī (1997) menghuraikan makna sabar yang terdapat dalam al-Quran secara umumnya boleh dibahagikan kepada dua, iaitu:

i. Sabar daripada melakukan perbuatan keji, mungkar dan permusuhan.

ii. Sabar berkaitan dengan menegakkan keadilan, melakukan kebaikan dan memberikan infaq.

Bahagian pertama tentang sabar sebagaimana yang dinyatakan di atas merujuk kepada kesabaran dalam memerangi hawa nafsu yang bersumberkan dari hati, rayuan musuh serta keindahan dunia. Dalam hal ini, seseorang perlu sentiasa bersabar dalam mengabdikan diri kepada Allah SWT dan menahan anggota badan agar tidak menuruti hawa nafsu. Usaha ini dilakukan bagi memastikan seseorang sentiasa berada di jalan Allah SWT, mampu mengendalikan perkataan, menguruskan hati dan badan. Dengan begiru, buah daripada kesabaran berupaya menetapkan kedudukan jiwa agar sentiasa beribadah kepada Allah SWT serta menekan diri supaya sentiasa bersifat qañ 'ah atau berpada-pada ke atas rezeki yang diberi olehNya.

Manakala bahagian kedua sabar merujuk kepada kesabaran dalam menghadapi cubaan dan ujian. Sabar ini merupakan di antara sifat orang-orang yang adil dan muhșin (orang yang selalu melakukan kebaikan). Sabar kategori ini juga dapat diertikan sebagai menginfaqkan harta serta memberi hak kepada ahlinya. Di sini alMakkī mengutamakan pemberian infak ke atas kaum kerabat seseorang. Selain itu, juga termasuk kategori sabar ini iaitu memerangi perbuatan keji dalam ilmu dan iman seperti sabar mencegah kemungkaran, sabar melarang perbuatan keji seperti bersikap keterlaluan, takabur serta berlebihan dalam hal-hal keduniaan. 


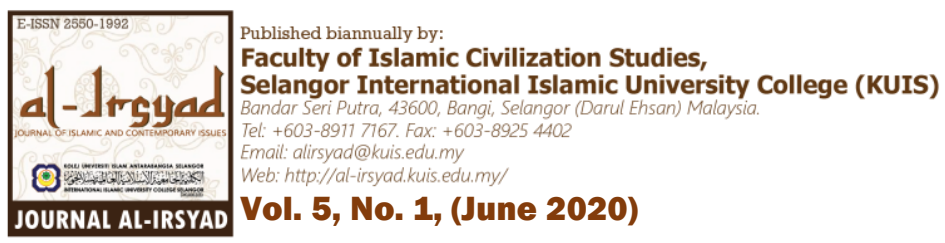

Pada wacana yang lain, al-Makkī (1997) turut menyatakan pandangan sebahagian ahli sufi yang membahagikan sabar kepada tiga makna, iaitu:

i. Tidak keluh kesah ketika mendapat musibah (maqam taubat).

ii. Reda dengan ketentuan dan ketetapan dari Allah SWT (maqam zuhud).

iii. Perasaan mahabbah terhadap segala ciptaanNya.

Dalam pengertian ini, seseorang hamba yang bersabar bukan sahaja telah mencapai maqam sabar bahkan merangkumi ketiga-tiga maqam yang lain, iaitu taubat, zuhud dan juga șiddī (membenarkan perasaan mahabbah terhadap ciptaan Allah SWT). Adapun berkiatan jenis sabar, al-Makkī menyebutkan lapan (8) perihal sabar sebagaimana ditunjukkan dalam jadual 1.

Jadual 1. Jenis-jenis sabar menurut al-Makkī

\begin{tabular}{|c|c|}
\hline Jenis Sabar & Huraian \\
\hline Pertama & $\begin{array}{l}\text { Sabar dalam beramal, iaitu sebelum, ketika dan sesudah beramal. Sabar sebelum beramal dijelaskan oleh al-Makkī } \\
\text { dengan membaiki niat. Manakala ketika beramal pula adalah dengan memastikan akad, amal dan sabar dalam } \\
\text { melaksanakannya. Manakala sabar sesudah beramal adalah sabar dalam menyembunyikan amal tersebut dari dilihat oleh } \\
\text { orang ramai. }\end{array}$ \\
\hline Kedua & $\begin{array}{l}\text { Sabar dalam menghadapi dugaan dan ujian dengan sentiasa bertawakkal kepada Allah SWT. Menurut al-Makkī, } \\
\text { sebahagian ahli sufi menyatakan hal tersebut termasuk ketegori sabar bersifat khusus yang hanya dialami oleh para nabi } \\
\text { dan rasul sahaja dalam menghadapi cubaan dan dugaan daripada Allah SWT. }\end{array}$ \\
\hline Ketiga & Sabar dalam melakukan kebaikan dan memerangi hawa nafsu agar sentiasa bertakwa kepada Allah SWT. \\
\hline Keempat & $\begin{array}{l}\text { Sabar dalam mendapat nikmat dari Allah SWT seperti nikmat sihat dan kekayaan dengan tidak menggunakan nikmat } \\
\text { tersebut ke arah keburukan. Al-Makki menyatakan sabar dalam kategori ini lebih berat untuk melaksanakannya } \\
\text { berbanding sabar dalam menghadapi dugaan. }\end{array}$ \\
\hline Kelima & Sabar dalam menyembunyikan musibah, rasa sakit dan gelisah dalam berdepan dengan ujian di hadapan orang lain. \\
\hline Keenam & Sabar dalam menyembunyikan amalan baik dan sedekah kecuali dapat mendatangkan kebaikan jika ditunjukkan. \\
\hline Ketujuh & $\begin{array}{l}\text { Sabar dalam berusaha untuk tidak malas, sabar dengan kehinaan, sabar dalam mementingkan hal-hal yang berkaitan } \\
\text { dengan akhirat berbanding dunia, sentiasa menjadikan Allah SWT sebagai landasan, tidak menentang dan } \\
\text { menyerupakan makna sifat ketuhanan. Sabar ini lebih menjurus kepada hal-hal yang berkaitan dengan akidah. }\end{array}$ \\
\hline Kelapan & $\begin{array}{l}\text { Sabar dalam memelihara keluarga dengan berusaha untuk mendapatkan rezeki dan memberi nafkah kepada ahli } \\
\text { keluarga. Menurut al-Makkī, dalam institusi keluarga sebenarnya mempunyai banyak jalan yang boleh menjadikan } \\
\text { seseorang itu lebih dekat kepada Allah SWT, seperti sentiasa reda dan bertawakkal dalam menguruskan dan menjaga } \\
\text { ahli keluarga dari terpesong ke arah keburukan. }\end{array}$ \\
\hline
\end{tabular}

Pengkaji menilai pengkelasan sabar oleh al-Makkī pada jadual 1 di atas membuktikan bahawa sabar dalam beramal mempunyai beberapa tahapan, yakni sebelum, semasa dan selepas beramal. Memperbaharui niat merupakan langkah awal daripada tahapan ini bagi memastikan memastikan amalan sabar ketika melaksanakannya. Bagi menyempurnakan tahapan ini, maka seseorang dituntut untuk menyembunyikan segala amal baik yang dibuat daripada tatapan orang ramai. Pada akhirnya kesemua jenis sabar yang dipaparkan perlu dilakukan dengan penuh komited dan berterusan.

\section{Implimentasi Sabar dalam Psikoterapi Pedofilia}

Isu pedofilia menurut Seto (2009) tiada kajian yang membuktikan bahawa pedofilia boleh diubah. Sebaliknya, intervensi yang dibentuk adalah untuk meningkatkan kawalan terhadap rangsangan seksual, mengurangkan keinginan seks, atau kemahiran pengurusan diri kepada individu yang bermotivasi untuk untuk mengelakkan tindakan terhadap tarikan seksual mereka. Terdapat beberapa kaedah yang telah digunakan oleh pakar untuk memulihkan ketagihan pedofilia, antaranya ialah Behavioural Treatments, Cognitive Behavioral Treatment, Drug treatment, dan Surgical castration (Jivin, J. G., Muhd. H. D., \& Suziyanah M. S., 2019).

Behavioural Treatments adalah teknik tingkah laku yang bermatlamat untuk mengajar individu pedofilia bagaimana untuk mengawal rangsangan seksual mereka. Sebgai contoh, teknik aversive conditioning digunakan untuk mengajar menahan rangsangan seksual terhadap kanak-kanak dengan pengulangan pemasangan noxious 


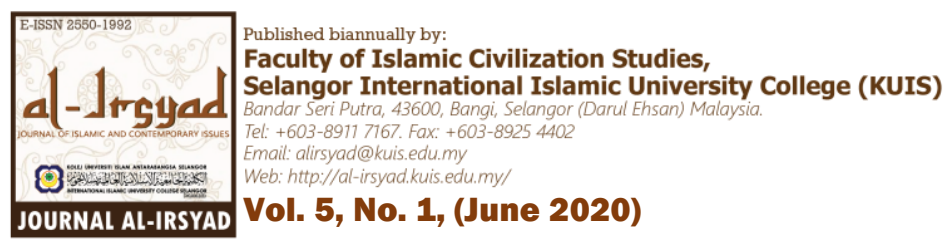

stimuli seperti bau yang tidak menyenangkan (ammonia) dengan rangsangan seksual yang menggambarkan kanak-kanak. Teknik tingkah laku mempunyai kesan terhadap corak rangsangan seksual dengan meningkatkan kawalan rangsangan seksual terhadap kanak-kanak (Lalumi ere \& Earls, 1992). Walau bagaimanapun, terdapat kurangnya bukti bahawa rangsangan seksual terhadap orang dewasa dapat ditingkatkan melalui peneguhan positif (Seto, 2009).

Cognitive Behavioral Treatment menyasarkan perangai, kepercayaan dan tingkah laku yang dipercayai untuk meningkatkan tindakan terhadap rangsangan seksual seseorang terhadap kanak-kanak. Bentuk terapi kognitif tingkah laku yang paling terkenal dan digunakan terhadap pesalah seks adalah pendekatan pencegahan relaps, yang diadaptasi dari bidang ketagihan (McGrath, Cumming, \& Burchard, 2003). Pendekatan pencegahan relaps termasuk (Seto, 2009):

i. Mengenal pasti situasi berisiko tinggi individu untuk relaps

ii. Mengenal pasti episod, iaitu tingkah laku yang tidak menyumbang kepada relaps tapi boleh membawa kepada relaps

iii. Membangunkan strategi untuk mengelakkan situasi berisiko tinggi seperti meluangkan masa bersendirian bersama kanak-kanak

iv. Membangunkan strategi mengatasi yang boleh digunakan dalam situasi berisiko tinggi yang tidak boleh dielakkan

v. Bertindak secara efektif kepada epsiod yang timbul

Drug treatment adalah intervensi perubatan yang sama seperti rawatan tingkah laku bertujuan untuk mengurangkan mengurangkan rangsangan seksual terhadap kanak-kanak dan cubaan mengurangkan tingkah laku seksual yang melibatkan kanak-kanak. Intervensi perubatan membuat cubaan dengan menyasarkan hormon atau neurotransmitters mendorong naluri, rangsangan, dan tingkah laku seksual. Terdapat beberapa sokongan tentang keberkesanan antiandrogens dalam mengurangkan kekerapan atau kekuatan naluri seksual. Gijs \& Gooren (1996) mengkaji literatur menilai kesan cyproterone acetate (nama dagang Androcur), yang menghalang pengambilan testosteron, dan medroxyprogesterone acetate (nama dagang Provera), yang mengurangkan pelepasan gonadotropin. Pengkaji lain telah mengkaji kesan ubat-ubatan lain, termasuk gonadotropin melepaskan hormon agonis seperti leuprolide acetate (nama dagang Lupron) yang menghalang pengeluaran testosteron dengan mengatasi peraturan pituitari, dan agen serotonergic terpilih yang mengurangkan naluri seksual (Seto, 2009).

Surgical castration mempunyai rasional yang sama seperti penggunaan antiandrogen untuk mengurangkan tindak balas seksual. Pembuangan testis hampir sepenuhnya menghilangkan pengeluaran androgen oleh endogen dan dengan itu boleh menyebabkan kesan pengurangan naluri seks yang sama seperti antiandrogen, tetapi dalam bentuk yang lebih kekal (Seto, 2009).

Secara umumnya, semua artikel yang dikaji menguatkan lagi bahawa rawatan pedofilia adalah isu yang relevan. Pelbagai kaedah perubatan dan psikologi telah digunapakai oleh pakar dalam merawat ketagihan pedofilia, namun masalah ini tidak dapat diselesaikan secara seratus peratus, kerana tahap kepulihan berada di tahap yang rendah. Justeru itu, pendekatan terapi jiwa berdasarkan teori al-Makkī merupakan sesuatu yang relevan dan konkrit untuk dijadikan sebagai rawatan terhadap apa jua masalah kejiwaan. Ini kerana pendekatan tasawuf dilihat menjadi satu alternatif yang sesuai dalam merawat penyakit psikologi (Khalid, 2008). Malah, pendekatan al-Makkī amat wajar kerana keseluruhan metodologinya merupakan pendekatan praktis atau amali secara berterusan, konsisten, menyeluruh yang boleh menjamin keberkesanan dalam perbentukan personaliti berpaksikan fitrah insan sebagaimana yang telah dibuktikan oleh perjalanan tamadun Islam (Syed Muhsin, 2012).

Al-Makkī (1997) telah menggariskan beberapa perkara berhubung dengan keutamaan dalam sabar, antaranya ialah Allah SWT telah menetapkan orang yang sabar sebagai imam kepada orang yang bertakwa serta dianugerahkan kemuliaan dan kemurahanNya. Hal ini al-Makkī sandarkan kepada firman Allah SWT dalam surah al-A'rāf ayat 137 :

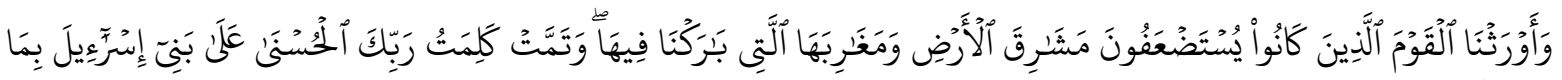

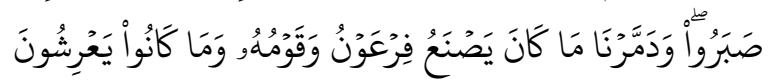




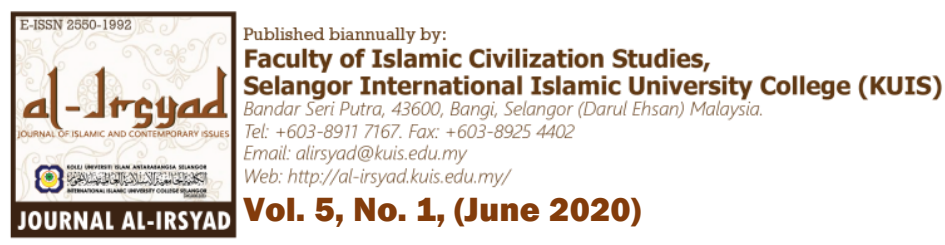

Maksudnya:

Kami wariskan kepada kaum (Bani Israil) yang telah tertindas itu akan daerah-daerah timur bumi (Palestin) dan daerah-daerah baratnya, yang Kami telah melimpahkan berkat padanya. Dan telah sempurnalah Kalimah Allah SWT (janjiNya) yang baik kepada kaum Bani Israil kerana kesabaran mereka (semasa mereka ditindas oleh Firaun), dan Kami telah hancurkan apa yang telah dibuat oleh Firaun dan kaumnya dan apa yang mereka telah dirikan (dari bangunan-bangunan yang tinggi).

Al-Makkī juga mengambil pendapat Ibn Mas'ūd RA yang menyatakan sabar itu sebagai salah satu daripada Rukun Iman. Pendapat ini juga turut dikemukakan oleh Sayyidina Ali dengan kata-katanya (al-Makkī, 1997):

"Kedudukan sabar dalam iman, seperti kepala dan badan. Tubuh badan tidak mungkin sempurna tanpa kepala. Begitu juga dengan iman tidak akan sempurna tanpa sabar”.

Memperkukuhkan lagi perihal keutamaan sabar ini, al-Makkī menambah bahawa Allah SWT telah menyebut perkataan sabar dalam al-Quran melebihi sembilan puluh (90) kali (al-Makkī, 1997). Pendapat ini diutarakan oleh Ibn Qudāmah (1988), manakala menurut Imam Aḥmad ibn Hanbal (Ibn Qayyim, 2000) dan alGhazālī (1986) pula menyatakan terdapat tujuh puluh tempat. Secara keseluruhannya, al-Makkī meletakkan sabar pada kedudukan yang tinggi, mulia, menjadi keutamaan dan penting (al-Qaradawi, 2004), memperoleh ganjaran berlipat ganda, dan sebahagian dari iman selepas maqam taubat dalam kehidupan manusia khususnya kepada ahli makrifah dalam perjalanan kerohanian mereka (al-Makkī, 1997).

Dari aspek spiritual, sabar juga salah satu kunci kepada ketenangan psikologi dalam Islam (Muhsin, 2018). Dengan kesabaran yang tinggi dapat menghasilkan output yang positif. Oleh yang demikian berdasarkan kepada pengertian yang telah dibuat oleh al-Makkī, seseorang itu mestilah melatih dirinya agar sabar dalam menghadapi musibah seperti tidak keluh kesah, menerapkan unsur reda dengan ketetapan dari Allah SWT dan cinta serta kasihkan segala ciptaanNya. Al-Makkī (1997) menegaskan bahawa sabar mendapat dugaan lebih utama kerana bebanannya lebih berat ditanggung oleh seseorang berbanding syukur.

Pada Jadual 2 ditunjukan tiga bentuk latihan sabar menurut al-Makkī yang saling berhubungan dalam menghasilkan rasa kehambaan dan penyerahan diri terhadap Allah SWT.

Jadual 2. Latihan sabar dan implementasi

\begin{tabular}{ccl} 
Bil. & \multicolumn{1}{c}{ Latihan sabar } & \multicolumn{1}{c}{ Implementasi } \\
\hline 1 & Sabar menghadapi musibah & Seorang pedofilia secara umumnya untuk pulih dari ketagihan seksual terhadap \\
& kanak-kanak perlu menanamkan azam dan tekad yang tinggi untuk bersabar dan \\
& melatih diri untuk sabar sepanjang proses rawatan pemulihan berlangsung.
\end{tabular}

Di samping itu, menganggap ketagihan seksual tersebut sebagai ujian dan sebab untuk taubat dan mendekatkan diri kepada Allah SWT.

$2 \quad$ Menerapkan unsur reda

Sebagai pedofil, setiap yang berlaku merupakan kerosakan yang dilakukan oleh tangan manusia dan atas izin Allah SWT sesuai dengan norma kehidupan. Pedofil perlu reda bahawa inilah jalan kehidupan yang perlu ditempuh, sebagai contoh dipenjarakan atas sebab jenayah pedofilia. Pedofil perlu reda dengan segala ketentuan Tuhan agar wujud dalam hati sifat bersangka baik kepada Allah SWT. Allah SWT berfirman dalam surah al-Baqarah ayat 216 yang bermaksud:

"Boleh jadi kamu membenci sesuatu, padahal ia amat baik bagimu, dan boleh jadi (pula) kamu menyukai sesuatu, padahal ia amat buruk bagimu; Allah SWT mengetahui, sedang kamu tidak mengetahui."

Justeru meredakan sesuatu akan membuka hati dan akal pedofil menilai dengan lebih hikmah setiap keadaan yang telah Allah SWT tentukan dalam kehidupannya.

3 Cinta dan kasihkan segala ciptaan Allah SWT
Seorang pedofil dalam ketagihannya terhadap kanak-kanak membuatkan dirinya hilang pertimbangan rasional, malah menepikan isu dosa dan pahala. Cinta dan kasihkan segala ciptaan Allah SWT adalah elemen yang sesuai untuk meneutralkan kembali orientasi seksual pedofilia. Dengan mengetahui dan memaknai nilai-nilai kemanusiaan yang lain dengan makna kasih sayang. Sebagai contoh membuat perumpamaan, bagaimana perasaan apabila mengetahui anak perempuan sendiri dirogol oleh pedofil yang lain. 


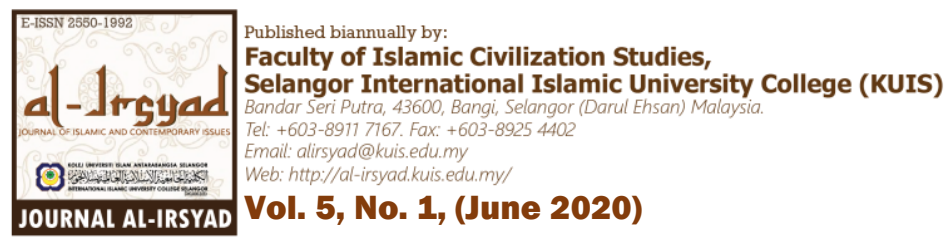

masalah sosial, trauma dan hidup dalam ketakutan. Ini adalah untuk memberi kesedaran kepada pelaku betapa besarnya impak yang dilakukan oleh pelaku, kerana telah merosakkan hidup seorang kanak-kanak.

Pedofil perlu mengetahui setiap ciptaan Allah SWT di dunia ini mempunyai hak untuk hidup aman, setiap kanak-kanak tersebut berhak untuk hidup ceria dan bahagia. Memaknai hidup orang lain, jangan biarkan pengalaman hidup sendiri mempengaruhi hidup orang lain.

Malah Allah SWT mengajarkan cara untuk mencintaiNya, sesuai dengan firman Allah SWT yang bermaksud:

"Katakanlah (wahai Muhammad): Jika benar kamu mengasihi Allah SWT maka ikutilah daku, nescaya Allah SWT mengasihi kamu serta mengampunkan dosa-dosa kamu. Dan (ingatlah), Allah SWT Maha Pengampun, lagi Maha Mengasihani." (Ali Imran:31)

Sabar dalam al-Quran kerap kali dikaitkan dengan ibadah solat, ini kerana sabar adalah satu ibadah hati yang perlu merujuk kepada pertolongan Allah SWT, iaitu berdoa agar hati, akal dan jasad turut sama bersabar (Shamsuddin, 2018). Allah SWT berfirman dalam surah al-Baqārah ayat 153 yang mengaitkan sabar dan solat:

Maksudnya:

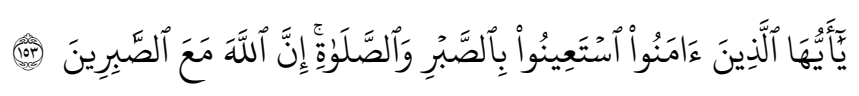

Wahai orang-orang yang beriman! Mohonlah pertolongan (kepada Allah SWT) dengan sabar dan solat. Sungguh Allah SWT berserta orang-orang yang sabar.

Berdasarkan ayat al-Quran di atas, konsep solat dan sabar mempunyai pertalian yang kukuh di antara satu sama lain, bermakna dalam tempoh seorang pedofilia melalui maqam sabar, fokus atau tunjang utamanya bermula dari ibadah solat. Sesuai dengan firman Allah SWT dalam surah al-Fatihah ayat 5 yang bermaksud: Kepada Engkau kami sembah, dan kepada Engkaulah kami mohon pertolongan). Justeru, istiqomah dalam melakukan ibadah solat juga memerlukan sabar, iaitu sabar dalam melakukan ketaatan kepada Allah SWT (alJawzīyyah, 1992). Di samping itu, dalam sebuah hadis Rasulullah SAW meletakkan elemen puasa sebagai latihan kepada maqam sabar:

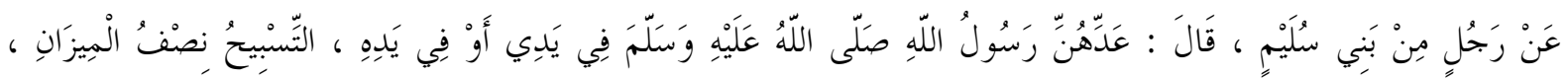

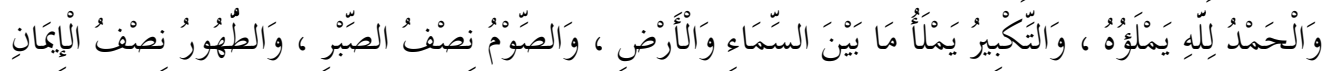

[al-Tirmidhi, Sunan al-Tirmidhi, Abwab ad'awat, no hadis 3519, hadis Hasan]

Maksudnya:

Seorang lelaki daripada Bani Sulaim berkata: Rasulullah SAW mengira-ngira dengan tangannya; Tasbih (Subhanallah) itu separuh daripada timbangan mizan, Alhamdulillah pula memenuhi timbangan itu, Takbir (Allahuakbar) pula mengisi apa yang ada antara langit dan bumi. Puasa itu separuh daripada kesabaran. Bersuci itu separuh keimanan.

Keadaan ini secara tidak langsung akan membuahkan rasa ketenangan dan kebahagiaan hati sekali gus mencerminkan perilaku yang terkawal dan positif. Justeru, sabar juga merupakan di antara pintu terbesar dalam melatih jiwa yang sedang dalam proses pemulihan (al-Makkī, 1997). Malahan, psikologis telah membuktikan bahawa kecelaruan mental dan spiritual mungkin berpunca dari ketiadaan perasaan sabar dalam menghadapi tekanan hidup seperti kesusahan, kematian, kegagalan dan sebagainya (Sa'ari, 2002), ini juga boleh dikaitkan dengan keadaan psikologi dan mental seseorang pedofilia.

Sabar dan istiqamah adalah salah satu prinsip penting yang mesti dimiliki sama ada oleh perawat mahupun pesakit (pedofilia). Ini adalah tahap yang boleh menjadikan urusan-urusan seseorang menjadi baik, sempurna dan memungkinkannya untuk mencapai manfaat-manfaat yang sentiasa teratur (al-Qushairī, 1999). Sabar menurut temu bual bersama responden (pesalah laku pedofilia) merujuk kepada sabar dan istiqomah dalam mengubah diri dan menjauhkan diri dari maksiat adalah antara kesedaran yang perlu ada pada setiap 


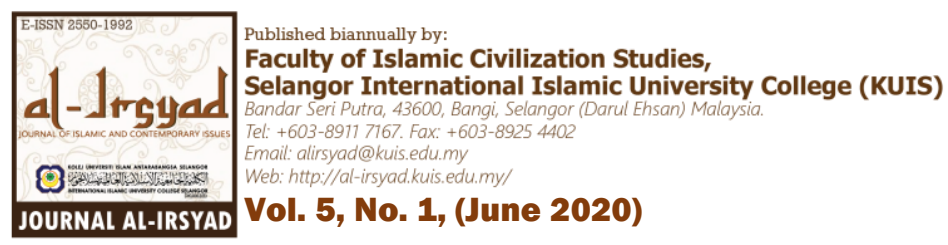

pesalah pedofilia dalam proses pemulihan diri (Pesalah, 23 Jun 2020). Pendekatan pemulihan yang dilakukan di penjara antaranya ialah pelaksanaan dan pengisian ibadah. Selama tempoh pesalah di penjara konsep sabar dalam ibadah perlu dipraktikkan sepanjang hari dengan tujuan dapat melembutkan dan membersihkan jiwa pesalah dari dosa dan maksiat (Pesalah, 23 Jun 2020).

\section{Kesimpulan}

Artikel ini membahaskan beberapa topik dalam maqam sabar yang boleh dijadikan sebagai elemen dalam merawat masalah ketagihan pedofilia. Antara topik yang dibincangkan ialah definisi maqam sabar, makna sabar menurut ahli sufi, jenis-jenis sabar, implementasi dan rangkaian ibadah untuk melatih sabar. Topik-topik tersebut dibahas mengikut perspektif al-Makkī berdasarkan karyanya kitab Qut al-Qulūb dalam perbahasan alMaqāmāt. Maqam sabar yang dibincangkan oleh al-Makkī merupakan salah satu usaha dan ikhtiar membantu kelompok pedofilia ini untuk kembali ke fitrah asal seksual mereka. Isu pedofilia ini perlu dilihat dengan serius, kerana ianya bukan kelompok seksual songsang seperti Lesbian, gay, biseksual dan transgender (LGBT). Bahkan perlakuan pedofilia termasuk dalam kesalahan undang-undang dan jenayah di Malaysia. Bukan negara ini sahaja bahkan seluruh dunia menganggap pedofilia sebagai satu kelompok jenayah yang perlu dipandang berat. Sehubungan dengan itu, dapatan kajian dalam artikel ini merupakan salah satu komponen utama pembangunan modul psikoterapi terhadap golongan pedofilia. Justeru, kajian ini diharap dapat memberi pendedahan dan impak kepada masyarakat sekali gus berusaha ke arah pembangunan generasi Rabbani sifar pedofilia.

\section{Penghargaan}

Penghargaan diberikan kepada Geran Penyelidikan dan Inovasi KUIS (GPIK) 2018. No Geran: 2018/RC/GPIKINHAD/003, Kolej Universiti Islam Antarabangsa Selangor (KUIS) yang bertajuk 'Psikoterapi Qurani dan Nabawi Bagi Pemulihan Salah laku Pedofilia Di Malaysia'.

\section{Rujukan}

'Abd al-Bāqī, F. A. (1981). al-Mu ‘jam al-Mufahras li alfāz al-Qur'ān al-Karīm. Kaherah: Dār al-Fikrī. Annemarie, S. (1975). Mystical dimensions of Islam. Chapel Hill: The University of North Carolina Press. Azra, A. (2008). Ensiklopedi Tasawuf. Jil. 1. Bandung, Indonesia: Angkasa.

Bowering, G. (1980). The Mystical vision of existence in classical Islam. New York, NY: Walter de Gruyter.

Gijs, L., \& Gooren L. (1996). Hormonal and psychopharmacological interventions in the treatment of paraphilias: An update. J. Sex Res. 33, 273-290. https://doi.org/10.1080/00224499609551845.

al-Hanbalī, A. F. (1932). Shadharāt al-Dhahāb fï Akhbār Man Dhahāb. Jil. 3. Kaherah: Maktabah al-Qudsī. Ibn Khallikān. (1977). Wafāyat al-A 'yān. ed. Iḥsān 'Abbās. Jil. 4. Beirut: Dār al-Șādir.

Ibn Qudāmah, A. R. (1988). Minhāj al-Qāṣidīn. Kaherah: Dār al-Turāth al-‘Arabī.

al-Jawzī, A. R. (1939). al Muntazām fī Tārīkh al-Mulūk wa al-Umām. Jil. 7. Haiderabad: Dā'irat al-Ma‘ārif. al-Jawzīyyah, I. Q. (2000). Madārīj al-Ṣalikīn Bayn Manāzīl Iyyaka Na’bud wa Iyyāka Nasța'īn. Jil. 2. Beirut: Dār Ihya' al-Turāth al-'Arabi.

al-Jawzīyyah. I. Q. (1992). Al-Da’wā al-Da’wā. Cairo: Dār al-Hadīth.

Jivin, J. G., Muhd. H. D., \& Suziyanah M. S. (2019). Pedofilia di Malaysia. PK6353 Psikopatologi. DOI: $10.13140 /$ RG.2.2.24977.99685.

Khalid, M. Y. (2008). Psychospiritual therapy approach for drug addiction rehabilitation. JAM,(3), $143-151$.

Lalumi`ere, M. L., \& Earls C. M. (1992). Voluntary control of penile responses as a function of stimulus duration and instructions. Behav. Assess. 14, 121-32.

al-Makkī, A. T. (1997). Qūt al-Qulūb fì Mu 'āmalah al-Mạ̣būb wa Wașf Ṭariq al-Murīd ilā Maqām al-Tawḥ̂̀d. Beirut: Dār al-Kutub al-'Ilmiyyah.

McGrath, R. J., Cumming, G. F., Burchard, B. L. (2003). Current practices and trends in sexual abuser management: The safer society 2002 nationwide survey. Brandon, VT: Safer Society Press.

Mohamed Ali, Z. (2019, August 13). Malaysia dan segelintir penghuni yang 'sakit'! Sinar Harian. Retrieved from https://www.sinarharian.com.my/article/42649/SUARA-SINAR/Analisis-Sinar/Malaysia-dansegelintir-penghuni-yang-sakit!

Mohd Amin, W. M. A. (1991). Evaluation of the Qut al-Qulub of al-Makki with an Anotated Translation of his Kitab al-Tawba (Tesis kedoktoran tidak diterbitkan), Universiti Edinburgh, Scotland, United Kingdom. 


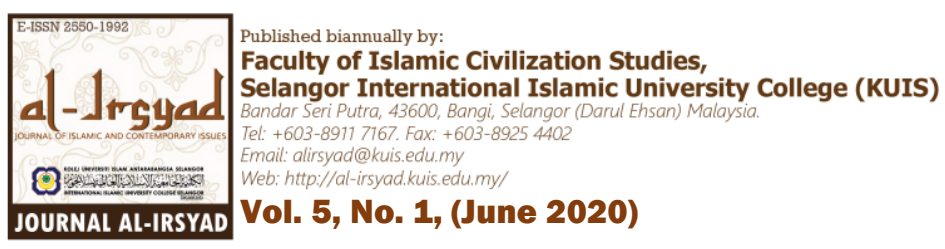

Muhsin, S. B. S. (2018). Sumbangan Abu Talib al-Makki terhadap pembangunan psikologi insan berdasarkan maqamat dalam Qut al-Qulub. Jurnal Akidah \& Pemikiran Islam, 20(1), 109-142.

al-Qaraḍāwī, Y. (2004). al-Tawakkal. Kaherah: Maktabah Wahbah.

al-Qushairī, N. (1999). Risalah al-Qushairiyyah fì 'ilmi al-Tașawwuf. Muhammad Lukman Hakim (Terj.). Surabaya: Risalah Gusti.

Reuters. (2016, 14 November). Paedophiles targeting Malaysia due to weak laws. News Straits Times. Retrieved from https://www.nst.com.my/news/2016/11/188502/paedophiles-targetingmalaysia-due-weak-laws.

Sa'ari, C. Z. (2002). A Purification of Soul According to Sufis: A Study of al-Ghazali's Theory. Jurnal Akidah \& Pemikiran Islam, 3(1), 95-112.

Seto, M. C. (2009). Pedophilia. Annual Review of Clinical Psychology, 5: 391-407. https://doi.org/10.1146/annurev.clinpsy.032408.153618.

Shamsuddin, M. A. (2018, 29 October). Tingkatkan sabar hadapi musibah. BH Online. Retrieved from https://www.bharian.com.my/rencana/agama/2018/10/491823/tingkatkan-sabar-hadapi-musibah.

Shukor, S. A., Shah, H. A. R., \& Musa, N. A. (2017). Regulating children's safety on the internet: a malaysian perspective. International Journal for Studies on Children, Women, Elderly And Disabled, 1(1), pp. $152-156$.

Smith, M. (1984). Rabi'a the mystic and her fellow-saints in Islam: Being the life and teachings of Rabi'a alAdawiyya al-Qaysiyya of Basra together with some account of the place of the women saints in Islam. New York, NY: Cambridge University Press.

Stapa, Z. (2003). Peranan dan sumbangan pendekatan tasawuf dalam menghadapi cabaran era globalisasi dan faham pasca moden. Dlm. Seminar Pemikiran Islam Peringkat Kebangsaan II, Akademi Pengajian Islam, Universiti Malaya.

Syed Muhsin, S. B. (2012). Kaedah psikoterapi berasaskan konsep maqamat: kajian terhadap kitab Qūt al-Qulüb Abū Țālib al-Makkī (Tesis kedoktoran tidak diterbitkan), Universiti Malaya. Kuala Lumpur, Malaysia.

Syed Muhsin, S. B. (2017). Kepulihan al-Halu' berasaskan maqamat Abu Talib al-Makki (W. 386 H) (Tesis kedoktoran tidak diterbitkan), Universiti Malaya. Kuala Lumpur, Malaysia.

Thye, L. L. (2016, 17 November). Address weaknesses to protect our children. News Straits Times. Retrieved from https://www.nst.com.my/news/2016/11/189322/address-weaknessesprotect-our-children.

Usman, A. H., \& Ahmad, H. (2019). Konsep firasat menurut al-Quran: Analisis tematik wacana mufasirin. AlIrsyad: Journal of Islamic and Contemporary Issues, 4(1), 1-11. Retrieved from http://alirsyad.kuis.edu.my/index.php/alirsyad/article/view/42

Usman, A. H., \& Shahabudin M. F. R. (2019). Analisis Literatur Sistematik Terhadap Keperluan Modul Psikoterapi Al-Quran: Tumpuan Pemulihan Salah Laku Pedofilia. Journal Sultan Alauddin Sulaiman Shah. Special Issues. 37-47.

Usman, A. H., Mohd Salleh, N., Shaharuddin, S. A., Nasir, M. N., Wazir, R., \& Shahabudin, M. F. R. (2019). Pedofilia Menurut Perspektif Al-Quran: Satu Analisis Tematik. E-proceeding Persidangan Antarabangsa Sains Sosial dan Kemanusiaan. 19-30. 